\title{
NZ's Pharmac negotiates deal for molnupiravir to treat COVID-19
}

New Zealand's Pharmaceutical Management Agency (Pharmac) has negotiated a deal with Merck, Sharp and Dohme (MSD) to purchase the antiviral, molnupiravir, for treating mild to moderate COVID-19 symptoms - subject to regulatory approval by Medsafe.

"MSD recently announced trial results showing that molnupiravir considerably reduced hospitalisations and deaths from COVID-19. While these are interim results, they are very promising", commented Pharmac's Chief Executive, Sarah Fitt.

"This is not the only new COVID-19 treatment we are working on. We are moving quickly to secure a range of new COVID-19 treatments for New Zealanders", adds Fitt.

Pharmac is proactively engaging global pharmaceutical companies to secure access to safe, effective COVID-19 treatments in New Zealand to help manage the ongoing health risks posed by COVID-19.

Pharmaceutical Management Agency (PHARMAC). Pharmac negotiates deal for molnupiravir to treat COVID-19. Internet Document : 11 Oct 2021. Available from: URL: https://pharmac.govt.nz/news-and-resources/news/2021-10-11-media-release-pharmac-negotiates-deal-for-molnupiravir-to-treat-covid-19/ 